\title{
Kinetic Spectrophotometric Determination of Betahistine Dihydrochloride and Etilefrine Hydrochloride in Pharmaceutical Formulation
}

\author{
Sara M. Anis*, Mervat M. Hosny, Hisham E. Abdellatef, Mohamed N. El-Balkiny
}

Faculty of Pharmacy, Department of Analytical Chemistry, Zagazig University Zagazig, Egypt - postal code: 44519

\begin{abstract}
The importance of betahistine dihydrochloride as an anti-vertigo medicine and of etilefrine hydrochloride in the management of hypotension necessitates the development of a simple, sensitive and inexpensive technique for their analysis. This study reports the development of an accurate, feasible kinetic technique for their determination. It is based on the reaction of the cited drugs with 4-chloro-7-nitrobenzofurazan (NBD-Cl) in presence of $0.05 \mathrm{M}$ disodium hydrogen phosphate. The absorbance was measured at 496, and $503 \mathrm{~nm}$ for betahistine dihydrochloride and etilefrine hydrochloride respectively, at a fixed time of 30 minutes on thermostated water bath at $90^{\circ} \mathrm{C}$. The absorbance concentration plots were rectilinear over the range $0.25-7$ and $3-13 \mu \mathrm{g} / \mathrm{ml}$ for betahistine dihydrochloride and etilefrine hydrochloride, respectively. The method has been applied successfully to commercial tablet dosage form and can be further applied for their determination on a large scale in quality control laboratories, or in small laboratories. The obtained results statistically agreed with those obtained by official titrimetric methods. The determination of the studied drugs by the fixed concentration and rate constant methods is feasible with the calibration equations obtained, but the fixed time method proves to be more applicable.
\end{abstract}

Keywords: Kinetic determination; Betahistine dihydrochloride; Etilefrine hydrochloride; 4-Chloro-7-nitrobenzofurazan (NBD-Cl)

\section{Introduction}

Betahistine dihydrochloride [N-Methyl-2-(2-pyridyl) ethylamine dihydrochloride] is an analogue of histamine and is claimed to improve the microcirculation of the labyrinth resulting in reduced endolymphatic pressure. It is used to reduce the symptoms of vertigo, tinnitus, and hearing loss associated with Ménière's disease. Etilefrine hydrochloride [2-Ethylamino-1-(3-hydroxyphenyl) ethanol hydrochloride] is a direct-acting sympathomimetic with beta1-agonist properties, and some alpha- and beta2-agonist actions. It is used for the treatment of hypotensive states [1]. Few methods have been reported for the determination of betahistine dihydrochloride including spectrophotometry [2-6], atomic absorption spectrometry [4], capillary electrophoresis [7] and HPLC [4, 8-10].

Different techniques were also reported for the determination of etilefrine hydrochloride including: spectrophotometry [11-13], automated sequential injection spectrophotometry [14], Flow-injection spectrophotometry [15], flow-injection chemiluminometric assay [16] and HPLC [17-18].

$\mathrm{NBD}-\mathrm{Cl}$ is an electroactive halide reagent, it has been used as a fluorogenic or chromogenic reagent in pharmaceutical analysis, it has also been used in charge transfere reactions due to its electrophilic properties, where it acts as $\pi$ acceptor. The analysis of different compounds or drugs either in pharmaceuticals or in biological samples was performed after derivatization with NBD-Cl followed by measuring the resulted product by means of: spectrophotometer,spectrofluorimet ry and liquid chromatography [19-21].

To our best knowledge no attempts have yet been made to determine both drugs by any kinetic method. Furthermore, some specific advantages in the application of kinetic assay can be expected [22], e.g. (a) Selectivity due to the measurement of the evolution of the absorbance with the time of reaction instead of measuring the concrete absorbance value; (b) Possibility of no interference of the colored and/or turbidity background of the samples, and (c) Possibility of no interference of the other active compounds present in the commercial product if they are resisting the chemical reaction conditions established for the proposed kinetic method.

The aim of the present work was the development of simple, sensitive and economical kinetic analytical method for the determination of betahistine dihydrochloride and etilefrine hydrochloride in their pure form and in their pharmaceutical formulations by measuring the absorbance at 496, and $503 \mathrm{~nm}$ for both drugs respectively after the addition of NBD-Cl.

\section{Experimental}

\section{Apparatus}

Shimadzu UV-260 double beam recording spectrometer with a 1 cm cell holder

\section{Materials and reagents}

All reagents and solvents were of analytical grade, doubly distilled water was used.

- Disodium hydrogen phosphate (El-Nasr Chemical Co. Cairo, Egypt), $0.05 \mathrm{M}$ aqueous solution.

- 4-chloro-7-nitrobenzofurazan (NBD-Cl) (Fluka- Germany), a fresh solution $(0.1 \% \mathrm{w} / \mathrm{v})$ in methanol was prepared daily.

- Betahistine dihydrochloride pure drug (Pharco Co., Egypt),

*Corresponding author: Sara M. Anis, Faculty of Pharmacy, Department of Analytical Chemistry, Zagazig University Zagazig, Egypt - postal code: 44519 Tel: +201 073076 04; Fax: +20 55 2303266; E-mail: sara-anis@hotmail.com

Received November 22, 2010; Accepted December 15, 2010; Published February 25, 2011

Citation: Anis SM, Hosny MM, Abdellatef HE, El-Balkiny MN (2011) Kinetic Spectrophotometric Determination of Betahistine Dihydrochloride and Etilefrine Hydrochloride in Pharmaceutical Formulation. Pharm Anal Acta 2:116. doi:10.4172/2153-2435.1000116

Copyright: (C) 2011 Anis SM, et al. This is an open-access article distributed unde the terms of the Creative Commons Attribution License, which permits unrestricted use, distribution, and reproduction in any medium, provided the original author and source are credited. 
Citation: Anis SM, Hosny MM, Abdellatef HE, El-Balkiny MN (2011) Kinetic Spectrophotometric Determination of Betahistine Dihydrochloride and Etilefrine Hydrochloride in Pharmaceutical Formulation. Pharm Anal Acta 2:116. doi:10.4172/2153-2435.1000116

Page 2 of 6

Betaserc tablets (Pharco Co., Egypt), labeled to contain $8 \mathrm{mg}$ betahistine dihydrochloride per tablet, batch No. 296.

- Etilefrine hydrochloride (CID Co., Egypt), Effortil tablets (CID Co., Egypt), labeled to contain $5 \mathrm{mg}$ etilefrine hydrochloride per tablet, batch No. 105

\section{Standard drug solutions}

Aqueous solutions of $0.1 \mathrm{mg} / \mathrm{ml}$ betahistine dihydrochloride and etilefrine hydrochloride were prepared by dissolving appropriate amounts of each compound in distilled water.

\section{General procedures}

Construction of calibration curves: Accurately measured aliquots of standard solutions containing $(0.0025-0.07),(0.03-0.13) \mathrm{mg}$ of betahistine dihydrochloride and etilefrine hydrochloride respectively were transferred into a series of $10 \mathrm{ml}$ volumetric flasks, after that $1.5 \mathrm{ml}$ of $0.05 \mathrm{M}$ disodium hydrogen phosphate was added to bring the solution to $\mathrm{pH}$ of 9 , followed by $1.5 \mathrm{ml}$ of $0.1 \% \mathrm{w} / \mathrm{v} \mathrm{NBD}-\mathrm{Cl}$, the mixtures were heated to $90^{\circ} \mathrm{C}$ in a water bath for a fixed time of a 30 minutes, the flasks were cooled under water, volumes were made up to the mark using distilled water, the absorbance was measured directly at 496, $503 \mathrm{~nm}$ for the two drugs respectively. The concentration was then calculated from the corresponding equation for the calibration graph for the fixed time method (Tables 1-3).

Procedures for pharmaceutical formulations: Ten tablets were grinded, an accurately weighed amount equivalent to $10 \mathrm{mg}$ of both drugs was extracted by shaking with $10 \mathrm{ml}$ distilled water, filtered, transferred into separate $100 \mathrm{ml}$ volumetric flasks, completed to the mark using distilled water.

\section{Results}

\section{Optimization of the reaction's conditions}

The presence of nitro group in the $7^{\text {th }}$ position in NBD-Cl molecule induces a direct and indirect electrophilic reactivity. This can be also attributed to the strongly unsaturated character of nitro-benzofurazan system. The possibility of the reaction of NBD-Cl with betahistine dihydrochloride and etilefrine hydrochloride was investigated under various conditions. It was found that the reaction proceeds optimally

\begin{tabular}{|c|c|c|}
\hline Parameter & $\begin{array}{c}\text { Betahistine } \\
\text { dihydrochloride }\end{array}$ & $\begin{array}{c}\text { Etilefrine } \\
\text { hydrochloride }\end{array}$ \\
\hline Reaction Temperature $\left({ }^{\circ} \mathrm{C}\right)$ & 90 & 90 \\
Reaction Time $(\mathrm{min})$ & 30 & 30 \\
Reagent Volume & 1.5 & 1.5 \\
$(\mathrm{ml}$ of $0.1 \%$ w/v in methanol) & Water & Water \\
Solvent & 496 & 503 \\
\hline
\end{tabular}

Table 1: Assay parameters for the determination of betahistine dihydrochloride and etilefrine hydrochloride using fixed time method.

\begin{tabular}{|l|c|c|}
\hline \multicolumn{1}{|c|}{ Items } & $\begin{array}{c}\text { Betahistine } \\
\text { dihydrochloride }\end{array}$ & $\begin{array}{c}\text { Etilefrine } \\
\text { hydrochloride }\end{array}$ \\
\hline Linearity range (ig/ml ) & $0.25-7$ & $3-13$ \\
Apparant molar absorptivity* (mol $^{-1}$ & $4.76 \times 10^{4}$ & $1.51 \times 10^{4}$ \\
cm $^{-1}$ ) & $2.28 \times 10^{-2}$ & $6.92 \times 10^{-3}$ \\
Sandell's sensitivity (ìg/ml per 0.001 A) & & \\
Regression equation : & 0.189 & $-9.05 \times 10^{-5}$ \\
Intercept (a) & 0.107 & 0.069 \\
Slope (b) & 0.9999 & 0.9998 \\
Correlation coefficient (r) & 0.602 & 0.719 \\
Variance & & \\
\hline
\end{tabular}

*calculated on the basis of the molecular weight of the drug

Table 2: Spectral data for determination of betahistine dihydrochloride and etilefrine hydrochloride using fixed time method.

\begin{tabular}{|c|c|c|}
\hline Time (min) & Calibration equation & Correlation coefficient ( $r$ ) \\
\hline \multicolumn{3}{|c|}{ Betahistine dihydrochloride } \\
\hline 10 & $A=0.119+0.085 C$ & 0.9947 \\
\hline 20 & $A=0.155+0.101 C$ & 0.9950 \\
\hline 30 & $A=0.189+0.107 C$ & 0.9999 \\
\hline 40 & $A=0.089+0.114 C$ & 0.9983 \\
\hline \multicolumn{3}{|c|}{ Etilefrine hydrochloride } \\
\hline 10 & $A=-0.045+0.055 C$ & 0.9928 \\
\hline 20 & $A=-0.050+0.068 C$ & 0.9981 \\
\hline 30 & $A=-9.05 \times 10^{-5}+0.069 C$ & 0.9998 \\
\hline 40 & $A=-0.053+0.062 C$ & 0.9975 \\
\hline
\end{tabular}

Table 3: Calibration equations for betahistine dihydrochloride and etilefrine hydrochloride at different fixed times over the linearity range for both drugs, in presence of constant concentration of NBD-Cl.

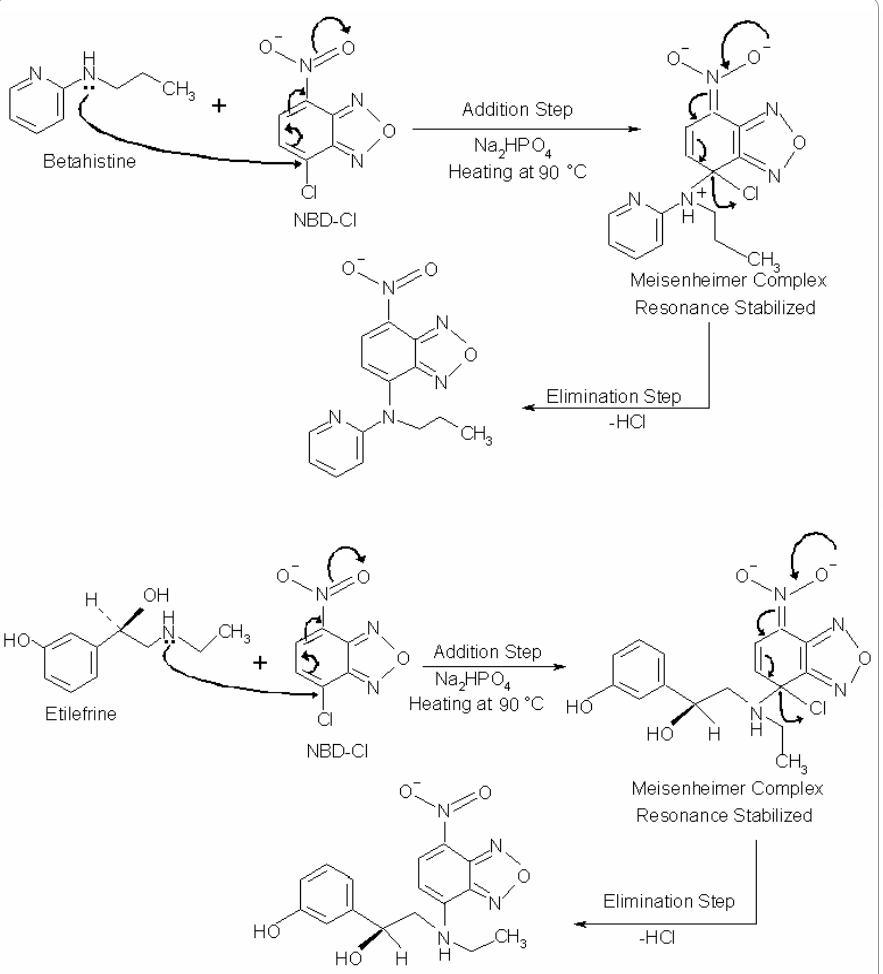

Scheme 1: Proposed reaction scheme for the reaction of NBD-Cl with: a) Betahistine dihydrochloride

b) Etilefrine hydrochloride

in alkaline media and at elevated temperatures. Like many alkylamine [23-24] betahistine dihydrochloride and etilefrine hydrochloride react with NBD-Cl to form brown color product (scheme 1), that absorbs at 496 and $503 \mathrm{~nm}$ for both drugs (Figure 1), respectively, the extent of the formation of this species depends on the concentration of $\mathrm{NBD}-\mathrm{Cl}$, alkalinity, temperature and therefore the effects of these variables were studied:

- Volume of $1.5 \mathrm{~mL}$ of $0.1 \% w / v \mathrm{NBD}-\mathrm{Cl}$ solution in methanol was found to be satisfactory and was used throughout this investigation.

- Different bases were tried in order to generate the nucleophile from the studied drugs such as disodium hydrogen phosphate, sodium bicarbonate, sodium acetate, and borax. The best results were obtained with $1.5 \mathrm{ml}$ of $0.05 \mathrm{M}$ disodium hydrogen phosphate.

- The reaction rate was found to increase with higher temperature 
Citation: Anis SM, Hosny MM, Abdellatef HE, El-Balkiny MN (2011) Kinetic Spectrophotometric Determination of Betahistine Dihydrochloride and Etilefrine Hydrochloride in Pharmaceutical Formulation. Pharm Anal Acta 2:116. doi:10.4172/2153-2435.1000116

with a subsequent increase in the slope of calibration graph (Table 3), indicating higher analytical sensitivity. Heating for 30 minutes was found to give most optimum results, further heating leads to decrease in the absorbance, and in the slope of calibration graph leading to a lower sensitivity.

\section{Kinetics study of the reactions}

The rate of the reaction was also found to be dependent on the drug concentration. The rate was followed at $90^{\circ} \mathrm{C}$ with various concentrations of the studied drugs in the range $0.25-7$ and 3-13 $\mu \mathrm{g} / \mathrm{ml}$ for betahistine dihydrochloride and etilefrine hydrochloride respectively, keeping the other reactants, base and $\mathrm{NBD}-\mathrm{Cl}$ at constant high concentration. The graph shown in (Figures 2, 3), was obtained, from which it is clear that the rate increases as the studied drugs concentration increases, indicating that the reactions rates obeys the following equation:

\section{Rate $=K^{\prime}[\text { drug }]^{\prime \prime}$}

where $\mathrm{K}^{\prime}$ is the pseudo-order constant of the reaction and $\mathrm{n}$ is the order of the reaction. The rate of the reaction may be estimated by the variable-time method measurement [25] as $\Delta \mathrm{A} / \Delta \mathrm{t}$, where $\mathrm{A}$ is the absorbance and $t$ is the time in seconds. Taking logarithms of rates and concentration (Table 4) equation (1) is transformed into:

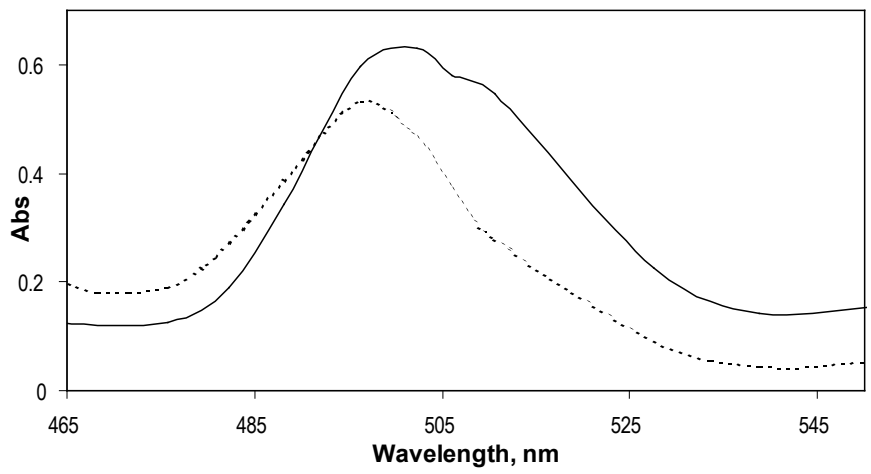

Figure 1: Absorption Spectra of the reaction products of the studied drugs with NBD-Cl.

........ Betahistine dihydrochloride $(3 \mu \mathrm{g} / \mathrm{ml})$

Etilefrine hydrochloride $(9 \mu \mathrm{g} / \mathrm{ml})$

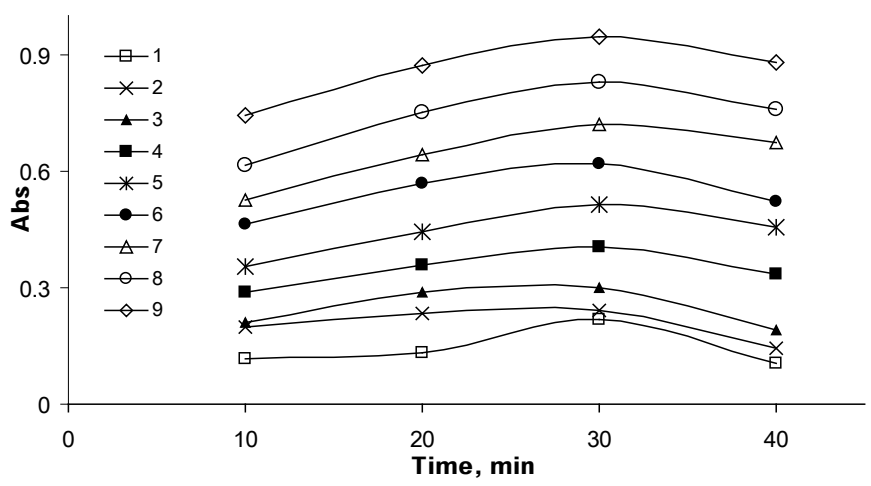

Figure 2: Absorbance vs. time graphs for the reaction of betahistine dihydrochloride and NBD-Cl, at fixed concentration of NBD-Cl and different concentration of betahistine dihydrochloride: (1) $1.19 \times 10^{-6}$; (2) $2.39 \times 10^{-6}$;

(3) $4.78 \times 10^{-6}$; (4) $9.56 \times 10^{-6}$; (5) $1.43 \times 10^{-5}$; (6) $1.91 \times 10^{-5}$; (7) $2.39 \times 10^{-5}$;

(8) $2.87 \times 10^{-5}$; (9) $3.35 \times 10^{-5} \mathrm{M}$ of the studied drug.

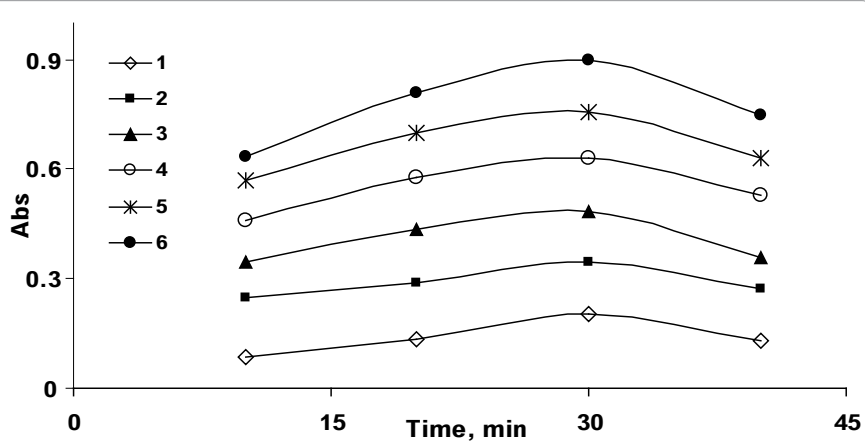

Figure 3: Absorbance vs. time graphs for the reaction of etilefrine hydrochloride and NBD-Cl, at fixed concentration of NBD-Cl and different concentration of etilefrine hydrochloride (1) $1.38 \times 10^{-5}$; (2) $2.29 \times 10^{-5}$; (3) $3.22 \times 10^{-5}$; (4) 4.13 $\times 10^{-5}$; (5) $5.05 \times 10^{-5}$; (6) $5.97 \times 10^{-5} \mathrm{M}$ of the studied drug.

\begin{tabular}{|c|c|c|c|}
\hline \multicolumn{2}{|c|}{ Betahistine dihydrochloride } & \multicolumn{2}{c|}{ Etilefrine hydrochloride } \\
\hline $\begin{array}{c}\text { Log (rate), } \\
\log \Delta A / \Delta t\end{array}$ & $\begin{array}{c}\text { Log (betahistine } \\
\text { dihydrochloride) (M) }\end{array}$ & $\begin{array}{c}\text { Log (rate), log } \\
\Delta A / \Delta t\end{array}$ & $\begin{array}{c}\text { Log (etilefrine } \\
\text { hydrochloride) (M) }\end{array}$ \\
\hline-4.602 & -5.922 & -4.071 & -4.861 \\
-4.436 & -5.621 & -4.176 & -4.639 \\
-4.139 & -5.320 & -3.829 & -4.493 \\
-3.933 & -5.019 & -3.709 & -4.384 \\
-3.824 & -4.843 & -3.664 & -4.296 \\
-3.757 & -4.718 & -3.538 & -4.224 \\
-3.714 & -4.621 & & \\
-3.645 & -4.542 & & \\
-3.661 & -4.475 & & \\
\hline
\end{tabular}

Table 4: Logarithms of the rates, of the reactions of different concentrations of betahistine dihydrochloride and etilefrine hydrochloride with $\mathrm{NBD}-\mathrm{Cl}$, at constant concentration of NBD-Cl.

$$
\log (\text { rate })=\log \Delta A / \Delta t=\log K^{\prime}+n \log [\text { drug] }
$$

Regression of $\log$ (rate) versus log (drug) gave the regression equation:

$\log ($ rate $)=-0.5402+0.6843 \log \mathrm{C}(r=0.9946), \mathrm{K}^{\prime}=0.288 \mathrm{~S}^{-1}$ for betahistine dihydrochloride $\log ($ rate $)=0.4032+0.9446 \log \mathrm{C}(\mathrm{r}=$ $0.9031), \mathrm{K}^{\prime}=2.531 \mathrm{~S}^{-1}$ for etilefrine hydrochloride hence the reaction is first order $(\mathrm{n} \approx 1)$ with respect to drug concentration.

\section{Evaluation of the kinetic methods}

Several experiments were carried out to obtain the drug concentration from the rate data according to the corresponding equation (1). Rate constant, fixed concentration and fixed time methods $[26,27]$ were tried and the most suitable analytical method was selected taking in consideration applicability, sensitivity and correlation coefficient.

Rate-constant method: Graphs of log (absorbance) versus time for the studied drugs concentrations in the range $\left(1.195 \times 10^{-6}\right.$ to $3.347 \mathrm{x}$ $10^{-5}$ and $1.378 \times 10^{-5}$ to $5.971 \times 10^{-5} \mathrm{M}$ ) for betahistine dihydrochloride and etilefrine hydrochloride respectively were plotted and all appeared to be rectilinear. Pseudo-first order rate constants corresponding to different drugs concentrations $(C)$ were calculated from the slopes multiplied by -2.303 and are presented in (Table 5), (Figure 4,5).

Regression of $(C)$ versus $K$ ' gave the equation:

$K^{\prime}=-0.0004+9.2297 C(r=0.4569) \quad$ (for betahistine dihydrochloride) 
Citation: Anis SM, Hosny MM, Abdellatef HE, El-Balkiny MN (2011) Kinetic Spectrophotometric Determination of Betahistine Dihydrochloride and Etilefrine Hydrochloride in Pharmaceutical Formulation. Pharm Anal Acta 2:116. doi:10.4172/2153-2435.1000116

Page 4 of 6

\section{$K^{\prime}=-0.0006+9.5836 C(r=0.7763) \quad$ (for etilefrine hydrochloride)}

The value $(r)$ indicates poor linearity, which is probably due to inconsistency of $K^{\prime}$ as a result of slight changes due to the elevated temperature of the reaction.

Fixed-concentration method: Reaction rates were determined for different concentrations in the range $1.913 \times 10^{-5}-2.869 \times 10^{-5}$ and 4.134 $\times 10^{-5}-5.972 \times 10^{-5} \mathrm{M}$ for betahistine dihydrochloride and etilefrine hydrochloride respectively. A pre -selected value of the absorbance was fixed, and the time was measured in seconds. The reciprocal of time (i.e. $1 / t$ ) versus the initial concentration of the studied drugs (Table 6) was plotted (Figure 6, 7). The following equations for calibration graphs were worked out by linear regression:

$1 / t=-1.7 \times 10^{-3}+116.11 C(r=0.9991)$ for betahistine

\begin{tabular}{|c|c|c|c|}
\hline \multicolumn{2}{|c|}{ Betahistine dihydrochloride } & \multicolumn{2}{c|}{ Etilefrine hydrochloride } \\
\hline $\mathrm{K}^{\prime}\left(\mathrm{S}^{-1}\right)$ & $(\mathrm{M})$ & $\mathrm{K}^{\prime}\left(\mathrm{S}^{-1}\right)$ & $(\mathrm{M})$ \\
\hline$-9.18 \times 10^{-4}$ & $1.19 \times 10^{-6}$ & $-6.84 \times 10^{-4}$ & $1.38 \times 10^{-5}$ \\
$-1.67 \times 10^{-4}$ & $2.39 \times 10^{-6}$ & $-2.99 \times 10^{-4}$ & $2.29 \times 10^{-5}$ \\
$-1.94 \times 10^{-4}$ & $4.78 \times 10^{-6}$ & $-1.78 \times 10^{-4}$ & $3.22 \times 10^{-5}$ \\
$-2.59 \times 10^{-4}$ & $9.56 \times 10^{-6}$ & $-1.46 \times 10^{-4}$ & $4.13 \times 10^{-5}$ \\
$-2.97 \times 10^{-4}$ & $1.43 \times 10^{-5}$ & $-1.26 \times 10^{-4}$ & $5.05 \times 10^{-5}$ \\
$-2.05 \times 10^{-4}$ & $1.91 \times 10^{-5}$ & $-1.78 \times 10^{-4}$ & $5.97 \times 10^{-5}$ \\
$-2.48 \times 10^{-4}$ & $2.39 \times 10^{-5}$ & & \\
$-1.98 \times 10^{-4}$ & $2.87 \times 10^{-5}$ & & \\
$-1.669 \times 10^{-4}$ & $3.35 \times 10^{-5}$ & & \\
\hline
\end{tabular}

Table 5: Pseudo-first order rate constants $K$, corresponding to different drugs concentrations, at constant concentration of NBD-Cl.

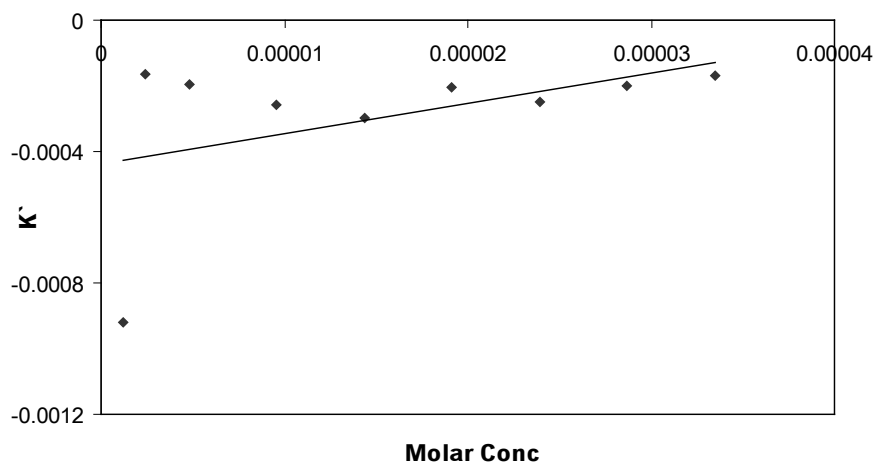

Figure 4: Values of Pseudo-first order rate constants $K^{\prime}$, for different concentrations of betahistine dihydrochloride at constant concentration of the reagent.

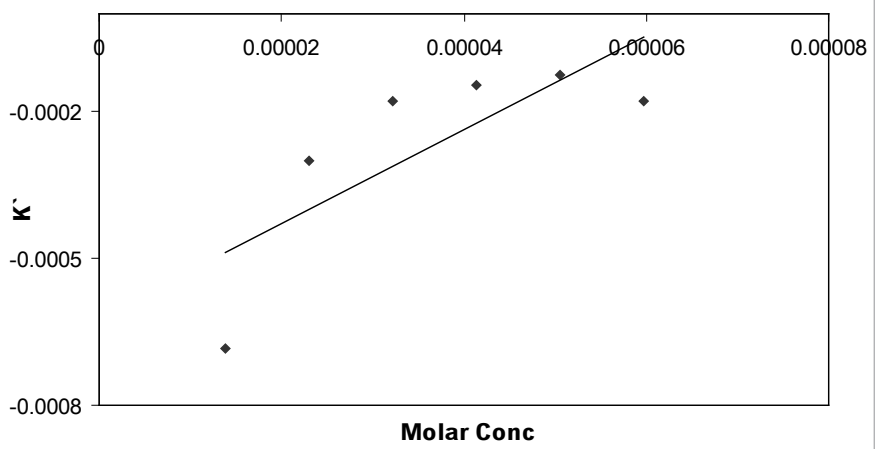

Figure 5: Values of Pseudo-first order rate constants K', for different concentrations of etilefrine hydrochloride at constant concentration of the reagent.

\begin{tabular}{|c|c|c|c|}
\hline \multicolumn{2}{|c|}{ Betahistine dihydrochloride } & \multicolumn{2}{|c|}{ Etilefrine hydrochloride } \\
\hline $1 / \mathrm{t}\left(\mathrm{S}^{-1}\right)$ & $(\mathrm{M})$ & $1 / \mathrm{t}\left(\mathrm{S}^{-1}\right)$ & $(\mathrm{M})$ \\
\hline $5.56 \times 10^{-4}$ & $1.91 \times 10^{-5}$ & $5.55 \times 10^{-4}$ & $4.13 \times 10^{-5}$ \\
$9.26 \times 10^{-4}$ & $2.39 \times 10^{-5}$ & $1.19 \times 10^{-3}$ & $5.05 \times 10^{-5}$ \\
$1.67 \times 10^{-3}$ & $2.87 \times 10^{-5}$ & $1.67 \times 10^{-4}$ & $5.97 \times 10^{-5}$ \\
\hline
\end{tabular}

Table 6: Values of reciprocal of time taken at fixed absorbance for different initia concentrations of betahistine dihydrochloride and etilefrine hydrochloride.

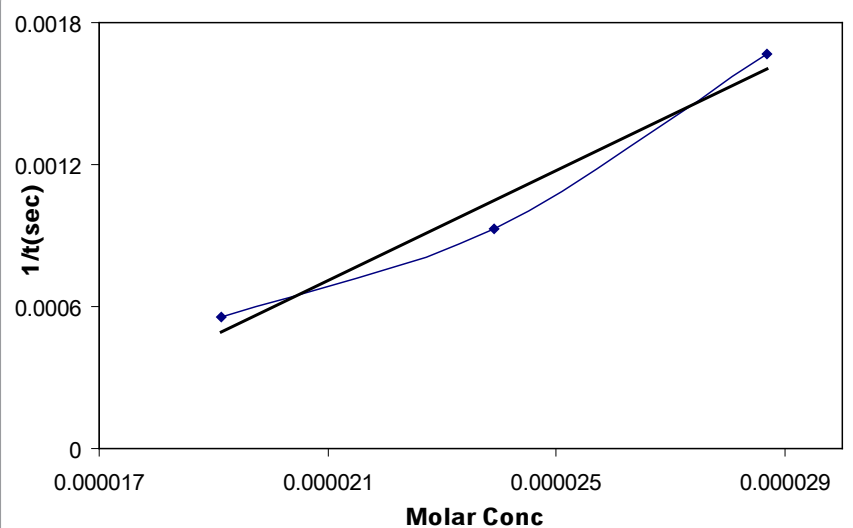

Figure 6: Values of reciprocal of time taken at fixed absorbance for different initial concentrations of betahistine dihydrochloride, at constant concentration of NBD-Cl.

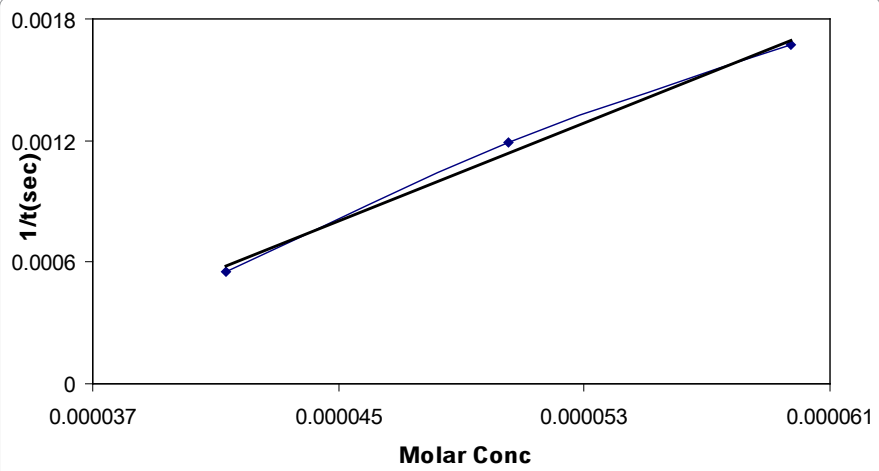

Figure 7: Values of reciprocal of time taken at fixed absorbance for different initial concentration of etilefrine hydrochloride, at constant concentration of NBD-Cl.

dihydrochloride $1 / t=-1.9 \times 10^{-3}+60.681 C(r=0.9967)$ for etilefrine hydrochloride.

The range of the concentration of the studied drugs giving the most acceptable calibration graph with the above equations was very limited, which could be disadvantage.

Fixed time method: Reaction rates were determined for different concentration of the studied drugs. At a pre-selected fixed time, which was accurately determined, the absorbance was measured. Calibration graphs of the absorbance versus initial concentration of the studied drugs were obtained at fixed times of 10,20,30 and 40 min with the calibration equation shown in (Table 3 ). It is clear that, both the slopes and intercepts increase with time. The most acceptable values of the correlation coefficient and more reaction products (indicated by higher absorbance readings) as shown in (Figures 2 and 3) were obtained for a fixed time of $30 \mathrm{~min}$, which was, therefore chosen as the most suitable time interval for measurements. 
Citation: Anis SM, Hosny MM, Abdellatef HE, El-Balkiny MN (2011) Kinetic Spectrophotometric Determination of Betahistine Dihydrochloride and Etilefrine Hydrochloride in Pharmaceutical Formulation. Pharm Anal Acta 2:116. doi:10.4172/2153-2435.1000116

Page 5 of 6

After optimizing the reaction conditions, the fixed time method was applied to the determination of betahistine dihydrochloride and etilefrine hydrochloride in pure form and in pharmaceutical formulation over the concentration range of $(0.25-7$ and $3-13 \mu \mathrm{g} / \mathrm{ml})$ for both drugs respectively. Analysis of the date gives the following regression equation:

$$
\begin{aligned}
& A=0.189+0.107 \mathrm{C}(\mathrm{r}=0.9999) \text { for betahistine dihydrochloride } \\
& \mathrm{A}=-9.05 \times 10^{-5}+0.069 \mathrm{C}(\mathrm{r}=0.9998) \text { for etilefrine hydrochloride }
\end{aligned}
$$

\section{Discussion}

The fixed time method was applied to the determination of the studied drugs in the pure form and in the supplied drug formulations (tablet form). The concentrations of the studied drugs were calculated using the corresponding calibration equation in (Table 3 ) at fixed time of $30 \mathrm{~min}$. The developed analytical method was validated as per USP requirements [29]. Under the described experimental conditions, calibration graphs were constructed for all of the studied

\begin{tabular}{|c|c|c|c|}
\hline \multicolumn{2}{|c|}{ Betahistine dihydrochloride } & \multicolumn{2}{|c|}{ Etilefrine hydrochloride } \\
\hline Taken $(\mu \mathrm{g} / \mathrm{ml})$ & Recovery \% & Taken $(\mu \mathrm{g} / \mathrm{ml})$ & Recovery \% \\
\hline $\begin{array}{c}0.25 \\
0.5 \\
1 \\
2 \\
3 \\
4 \\
5 \\
6 \\
7\end{array}$ & $\begin{array}{c}100.93 \\
100.93 \\
101.87 \\
100.00 \\
100.93 \\
100.00 \\
99.44 \\
99.69 \\
100.80\end{array}$ & $\begin{array}{c}3 \\
5 \\
7 \\
9 \\
11 \\
13\end{array}$ & $\begin{array}{c}99.04 \\
100.58 \\
100.00 \\
101.45 \\
99.47 \\
100.22\end{array}$ \\
\hline Mean* & 100.51 & & \\
\hline $\begin{array}{l}\text { N } \\
\text { S.D. } \\
\text { R.S.D. } \\
\text { V } \\
\text { S.E. }\end{array}$ & $\begin{array}{c}9 \\
0.776 \\
0.772 \\
0.602 \\
0.259\end{array}$ & & \\
\hline
\end{tabular}
drugs, linear relationship was found between the absorbance at $\lambda \max$

*Mean of three different experiments

Table 7: Determination of betahistine dihydrochloride and etilefrine hydrochloride

\begin{tabular}{|c|c|c|c|c|c|}
\hline \multicolumn{3}{|c|}{ Betahistine dihydrochloride } & \multicolumn{3}{|c|}{ Etilefrine hydrochloride } \\
\hline \multicolumn{3}{|c|}{ Betaserc Tablet } & \multicolumn{3}{|c|}{ Effortil Tablet } \\
\hline $\begin{array}{c}\text { Claimed } \\
\text { amount } \\
(\mu \mathrm{g} / \mathrm{ml})\end{array}$ & $\begin{array}{c}\text { Authentic } \\
\text { Added } \\
(\mu \mathrm{g} / \mathrm{ml})\end{array}$ & $\begin{array}{c}\text { Recovery } \\
\%\end{array}$ & $\begin{array}{c}\text { Claimed } \\
\text { amount }(\mu \mathrm{g} / \mathrm{ml})\end{array}$ & $\begin{array}{l}\text { Authentic } \\
\text { Added }(\mu \mathrm{g} / \\
\mathrm{ml})\end{array}$ & $\begin{array}{c}\text { Recovery } \\
\%\end{array}$ \\
\hline 0.25 & $\begin{array}{c}--- \\
0.5 \\
1 \\
2 \\
3 \\
5 \\
6\end{array}$ & $\begin{array}{c}100.93 \\
99.07 \\
99.07 \\
100.47 \\
100.62 \\
99.07 \\
100.47\end{array}$ & 3 & $\begin{array}{c}--- \\
3 \\
5 \\
7 \\
9 \\
11 \\
13\end{array}$ & $\begin{array}{c}98.56 \\
100.00 \\
100.87 \\
100.00 \\
99.52 \\
99.61 \\
101.00\end{array}$ \\
\hline \multicolumn{2}{|l|}{ Mean* } & 99.79 & \multicolumn{3}{|c|}{100.17} \\
\hline \multicolumn{2}{|l|}{$\mathbf{N}$} & 6 & \multicolumn{3}{|c|}{6} \\
\hline \multicolumn{2}{|l|}{ S.D. } & 0.798 & \multicolumn{3}{|c|}{0.631} \\
\hline \multicolumn{2}{|l|}{ R.S.D. } & 0.799 & \multicolumn{3}{|c|}{0.629} \\
\hline \multicolumn{2}{|l|}{$\mathbf{v}$} & 0.637 & \multicolumn{3}{|c|}{0.398} \\
\hline \multicolumn{2}{|l|}{ S.E. } & 0.326 & \multicolumn{3}{|c|}{0.257} \\
\hline
\end{tabular}
using fixed time method.

\section{*Mean of three different experiments}

Table 8: Application of standard addition technique for the determination of betahistine dihydrochloride and etilefrine hydrochloride using fixed time method.

\begin{tabular}{|c|c|c|c|c|}
\hline \multirow{2}{*}{ Items } & \multicolumn{2}{|c|}{ Betahistine dihydrochloride } & \multicolumn{2}{c|}{ Etilefrine hydrochloride } \\
\cline { 2 - 5 } & $\begin{array}{c}\text { Official } \\
\text { method }\end{array}$ & $\begin{array}{c}\text { Proposed } \\
\text { method }\end{array}$ & $\begin{array}{c}\text { Official } \\
\text { method }\end{array}$ & $\begin{array}{c}\text { Proposed } \\
\text { method }\end{array}$ \\
\hline Mean & 100.45 & 100.51 & 100.06 & 100.13 \\
$\left(\begin{array}{c}p=0.05) \\
\text { N }\end{array}\right.$ & 5 & 9 & 6 & 6 \\
S.D. & 0.674 & 0.776 & 0.655 & 0.848 \\
R.S.D & 0.671 & 0.772 & 0.654 & 0.847 \\
V & 0.454 & 0.602 & 0.429 & 0.719 \\
t & - & $0.145(2.179)^{*}$ & - & $0.159(2.228)^{*}$ \\
F & - & $1.33(3.84)^{*}$ & - & $1.68(5.05)^{*}$ \\
\hline
\end{tabular}

*Theoretical values of $\mathrm{t}$ and $\mathrm{F}$ at $\mathrm{p}=0.05$

Table (9): Statistical data for the determination of betahistine dihydrochloride and etilefrine hydrochloride using fixed time method compared with official methods [28].

and the concentration of the drug in the ranges of $0.25-7$ and $3-13$ $\mu \mathrm{g} / \mathrm{ml}$, for betahistine dihydrochloride and etilefrine hydrochloride respectively. The values for correlation coefficients ranged from 0.9998 to 0.9999 (Table 2). The recoveries, standard deviations, relative standard deviations, standard errors, variances for the two studied drugs applying the previously stated method were listed in (Table 7). The proposed method was applied for determination of the selected drugs in their pharmaceutical formulations using the standard addition method. The results of analysis of the commercial dosage forms and the recovery study are shown in (Table 8 ). The average percent recoveries obtained, indicated good accuracy of the methods.

The result obtained for the analysis of the studied drugs in drug formulations employed was compared with those obtained with the titrimetric methods [28], (Table 9). The Student t-test and F-test values of $95 \%$ confidence level did not exceed the theoretical values indicating no significant difference between the accuracy and the precision of the two methods.

\section{Conclusion}

The proposed method holds several advantages when compared to other previously reported methods:

a) In sensitivity when compared with the official titrational procedures [28]. The proposed method can be used for detection of as low as 0.25 or $3 \mu \mathrm{g} / \mathrm{ml}$ of betahistine dihydrochloride or etilefrine hydrochloride respectively while the lowest detection limit for the official method is 1.6 or $2.14 \mathrm{mg} / \mathrm{ml}$ for both drugs in same order.

b) In selectivity due to the measurement of the evolution of the absorbance with the time of reaction instead of the measurement of a concrete absorbance value, makes it advantageous over other reported spectrophotometric methods.

c) In contrast to HPLC which requires special hardware and is expensive both in instrument time and in solvent consumption. The reported method holds the advantages of requiring only standard spectrometer hardware.

In conclusion the given data reveal that the proposed method is accurate and sensitive, with good precision and accuracy. With this method, one can do accurate analysis at low cost without losing accuracy. The proposed method can be used as alternative methods to the reported ones for the routine analysis of betahistine dihydrochloride and etilefrine hydrochloride in the pure form and in pharmaceutical formulations, in quality control laboratories, or on smaller scale in small laboratories.

\section{References}

1. Sweetman SC (2007) Martindale, The Complete Drug Reference, 33rd Ed., Pharmaceutical Press, London. 
Citation: Anis SM, Hosny MM, Abdellatef HE, El-Balkiny MN (2011) Kinetic Spectrophotometric Determination of Betahistine Dihydrochloride and Etilefrine Hydrochloride in Pharmaceutical Formulation. Pharm Anal Acta 2:116. doi:10.4172/2153-2435.1000116

2. Salman S, Akkucuk E, Gezginci H (1991) Spectrophotometric determination of betahistine dihydrochloride with chloranil. Acta Pharm Turc 33: 75-78.

3. Tripathi DK, Ganguli A (1995) Spectrophotometric determination of betahistine hydrochloride in tablet dosage form. Eastern Pharmacist, 38(454), 149-150, [1995]

4. EI-Walily AFM, Razak OA, Belal SF, Bakry RS (1999) Utilization of carbon disulphide for the analytical determination of betahistine hydrochloride and captopril in their pharmaceutical preparations. J Pharm Biomed Anal 21: 439449.

5. Zhao YX, Li SQ (2000) Ultra-violet spectrophotometric determination of the content of betahistine mesylate in tablets and homogeneity studies. Yaowu Fenxi Zazhi 20: 64-65.

6. Lian-Hui C, Zhang B, Shao-Pu L, Jian Y, Hong-Ming L (2005) Spectrophotometric determination of the main compound in betahistine hydrochloride sodium chloride injection solution. Kexue Chubanshe 22: 1116-1117.

7. Sun XH, Yang XR, Wang EK (2003) Evaluation of a sol-gel derived carbon composite electrode as an amperometric detector for capillary electrophoresis. J Chromatogr 991: 109-116.

8. Chen RJ, Jin SZ (1995) HPLC determination of betahistine hydrochloride in oral-medication solutions. Yaowu-Fenxi-Zazhi 15: 56-57.

9. Rong L, Jin S, Jinling F, Yinghua S, Xiaohong L, et al. (2006) Determination of betahistine hydrochloride and the related substances of betahistine hydrochloride injection by HPLC. Shenyang Yaoke Daxue Xuebao Bianjibu 23: 448-451.

10. Tang K (2006) RP-HPLC determination of betahistine tablets. Yaowu Fenx Zazhi 26: 502-504.

11. Bakry RS, EI Walily AFM, Belal SF (1995) Spectrophotometric determination of etilefrine, ritodrine, isoxsuprine and salbutamol by nitration and subsequent Meisenheimer complex formation. Anal Lett 28: 2503-2519.

12. Bakry RS, EIWalily AFM, Belal SF (1997) Spectrophotometric determination of some phenolic sympathomimetic drugs through reaction with 2,6-dihaloquinone chlorimides. Mikrochim Acta 127: 89-93.

13. Ragab GH, Elmasry MS, Aboul-Kheir AA (2004) Spectrophotometric determination of some drugs containing phenolic group using 3-methyl-2benzothiazolinon hydrazone hydrochloride (MBTH). Egypt J Pharm Sci 45 : 21-32.

14. Negussie WB, Jacobus FS, Raluca IS (2004) Sequential injection spectrophotometric determination of etilefrine hydrochloride. FARMACO 59 : 1005-1010.

15. El-Gendy AE (2000) Flow Injection Analysis of Some Phenolic Sympathomimetic Drugs. Anal Lett 33: 2927-2938.
16. Aly FA, Al-Tamimi SA, Alwarthan AA (2000) Determination of phenolic sympathomimetic drugs in pharmaceutical samples and biological fluids by flow-injection chemiluminescence. J AOAC Int 83: 1299-1305.

17. Ullrich T, Menge S, Schmid M, Guebitz G, Krauss G (2001) Enantioselective high-performance liquid chromatography of therapeutically relevan aminoalcohols as their fluorescent 1-naphthyl isocyanate derivatives. J Biomed Chromatogr 15: 212-216

18. Kojima K, Yamanaka M, Nakanishi Y, Arakawa S (1990) High-performance liquid-chromatographic determination of etilefrine in human plasma using combined solid-phase and organic-solvent extraction and electrochemical detection. J Chromatogr Biomed App 90: 210-217.

19. El-Enany N, Ahmida N, Belal F (2009) Spectrofluorimetric and spectrophotometric determination of oxamniquine in pharmaceuticals and biological fluids via derivatization with 4-chloro-7-nitrobenzo-2-oxa-1,3-diazole (NBD-Cl). J Chin Chem Soc 56: 485-492.

20. Ulu S (2009) Spectrofluorimetric determination of fluoroquinolones in pharmaceutical preparations. Spectrochim Acta A Mol Biomol Spectrosc 72 138-143.

21. Bahrami G, Mohammadi B (2006) Sensitive microanalysis of gabapentin by high-performance liquid chromatography in human serum using pre-column derivatization with 4-chloro-7-nitrobenzofurazan. J Chromatogr B 83: 24-28.

22. Espinosa-Mansilla A, Acedo Valenzuela MI, Salinas F, Canada F (1998) Kinetic determination of ansamicins in pharmaceutical formulations. Anal Chim Acta 376: $365-375$

23. Van Hoof F, Heyndrickx A (1974) Thin layer chromatographic spectrophotofluorometric analysis of amphetamine and amphetamine analogs after reaction with 4-chloro-7-nitrobenzo-2,1,3-oxadiazole. Anal Chem 46: 286-288.

24. De La Pena L, Gomez Hens A, Perez Bendito D (1995) Kinetic determination of nortriptyline in pharmaceutical samples by use of photometric and fluorimetric detection. J Pharm Biomed Anal 13: 199-203.

25. Weisberger A, Friess SL, Lewis ES (1953) Techniques of Organic Chemistry, vol. 3, Interscience, New York, 1953 Part III.

26. Yatsimirskii KB (1966) Kinetic Methods of Analysis, Pegamon Press, Oxford

27. Laitinen HA, Harris WE (1975) Chemical Analysis, second ed., McGraw-Hill, New York

28. British Pharmacopoeia, The stationary office (2007) London.

29. United States pharmacopeia, 25 revision (2001) the national formulary, the United States pharmacopeial convention, Mack, Easton. 